\title{
The Role of Intestinal Fatty Acid Binding Proteins in Protecting Cells from Fatty Acid Induced Impairment of Mitochondrial Dynamics and Apoptosis
}

\author{
Suparna Sarkar-Banerjee ${ }^{a}$ Sourav Chowdhury ${ }^{b}$ Dwipanjan Sanyal ${ }^{b}$ Tulika Mitrac \\ Sib Sankar Royc Krishnananda Chattopadhyay ${ }^{\mathrm{b}}$ \\ aDepartment of Integrative Biology and Pharmacology, The University of Texas Medical School, \\ Houston, USA, bProtein Folding and Dynamics Laboratory, Structural Biology and Bioinformatics \\ Division, CSIR-Indian Institute of Chemical Biology, Kolkata, 'Cell Biology and Physiology Division, CSIR- \\ Indian Institute of Chemical Biology, Kolkata, India
}

\section{Key Words}

Intestinal fatty acid binding protein $\bullet$ Lipid toxicity $\bullet$ Mitochondrial dynamics $•$ Apoptosis

\begin{abstract}
Background/Aims: The conformation, folding and lipid binding properties of the intestinal fatty acid binding proteins (IFABP) have been extensively investigated. In contrast, the functional aspects of these proteins are not understood and matter of debates. In this study, we aim to address the deleterious effects of FA overload on cellular components, particularly mitochondria; and how IFABP helps in combating this stress by restoring the mitochondrial dynamics. Methods: In the present study the functional aspect of IFABP under conditions of lipid stress was studied by a string of extensive in-cell studies; flow cytometry by fluorescenceactivated cell sorting (FACS), confocal imaging, western blotting and quantitative real time PCR. We deployed ectopic expression of IFABP in rescuing cells under the condition of lipid stress. Again in order to unveil the mechanistic insights of functional traits, we arrayed extensive computational approaches by means of studying centrality calculations along with proteinprotein association and ligand induced cluster dissociation. While addressing its functional importance, we used FCS and in-silico computational analyses, to show the structural distribution and the underlying mechanism of IFABP's action. Results: Ectopic expression of IFABP in HeLa cells has been found to rescue mitochondrial morphological dynamics and restore membrane potential, partially preventing apoptotic damage induced by the increased FAs. These findings have been further validated in the functionally relevant intestinal Caco-2 cells, where the native expression of IFABP protects mitochondrial morphology from abrogation induced by FA overload. However, this native level expression is insufficient to protect against

S. Sarkar-Banerjee and S. Chowdhury contributed equally to this work.

Krishnananda
Chattopadhyay, Ph.D.

Structural Biology and Bioinformatics Division, CSIR-Indian Institute of Chemical Biology
4, Raja S.C. Mullick Road, Kolkata 700032 (India)
\end{abstract}

KARGER 
Sarkar-Banerjee et al.: Ameliorating Lipid Induced Cellular Toxicity by the Intestinal Fatty Acid Binding Protein

apoptotic cell death, which is rescued, at least partially in cells overexpressing IFABP. In addition, shRNA mediated IFABP knockdown in Caco-2 cells compromises mitochondrial dynamics and switches on intrinsic apoptotic pathways under FA-induced metabolic stress. Conclusion: To summarize, the present study implicates functional significance of IFABP in controlling ligandinduced damage in mitochondrial dynamics and apoptosis.

\section{Introduction}

Fatty acid binding proteins (FABPs) have long been known as classes of intracellular proteins of varied functions [1-3]. They have been referred to as "lipid chaperones" [4] for their roles in escorting lipids to different cellular compartments. FABPs are also known to modulate various metabolic signaling pathways and participate in multiple enzymatic activities $[5,6]$. These are 14-15 $\mathrm{kDa}$ protein molecules that bind strongly and reversibly to hydrophobic ligands [7]. These proteins are armed with conformational switches which craft the folding landscapes, thereby deciding the functional conformation [8] [9]. Although the exact biological role and mechanism of actions of FABPs are yet to be known, their participation in storage, trafficking and metabolism of FA have been explored. There are approximately nine known classes of FABPs that are expressed differentially in various tissues engaged in active lipid metabolism [1].

Intestinal fatty acid binding protein (IFABP) is abundantly found in epithelial cells of small intestine $[10,11]$. Among others, liver FABP (L-FABP) is also expressed in the intestine along with IFABP, though the expression of IFABP is more prevalent than that of LFABP [11]. FABPs are a class of fatty acid transport proteins that ferry ligands to different subcellular compartments for the FA utilization and metabolism [12-14]. Extensive research has been devoted to explore the conformational changes and ligand binding affinities in vitro $[15,16]$.

Although the functional aspects of IFABP have been widely debated and conflicting results do exist, the role of these proteins in lipid homeostasis has been recognized. The term homeostasis encompasses the underlying mechanisms by which cells try to maintain intracellular balance against extrinsic as well as intrinsic challenges. IFABPs, like other FABPs, receive, import and ferry their lipid ligands to respective metabolic sites [17-19]. IFABP localizes in the peri-nuclear regions with less diffused cytoplasmic existence in the absence of its FA ligand [20]. Lipids are essential for several cellular functions, sources of cellular energy [21] and can modulate signaling pathways. However, excess lipids impose stressful effects on cellular machineries [22]. Increased lipids (or, FA) have been reported to initiate apoptosis, cellular insulin resistance and pancreatic $\beta$-cell failure in diabetes mellitus [22]. It has also been reported earlier that the treatment of cells with high concentrations of FA elicits pathological conditions including oxidative stress, cytotoxicity and apoptosis [23-25]. In this context, to prove the role of IFABP in cellular milieu, we have induced FA overload and studied various cellular changes both in the absence and presence of ectopically expressed IFABP.

In the present FA-overload model, we tested whether exogenously added FA would cause cellular stress and alter sub cellular organelle dynamics. Fig. 1 shows a

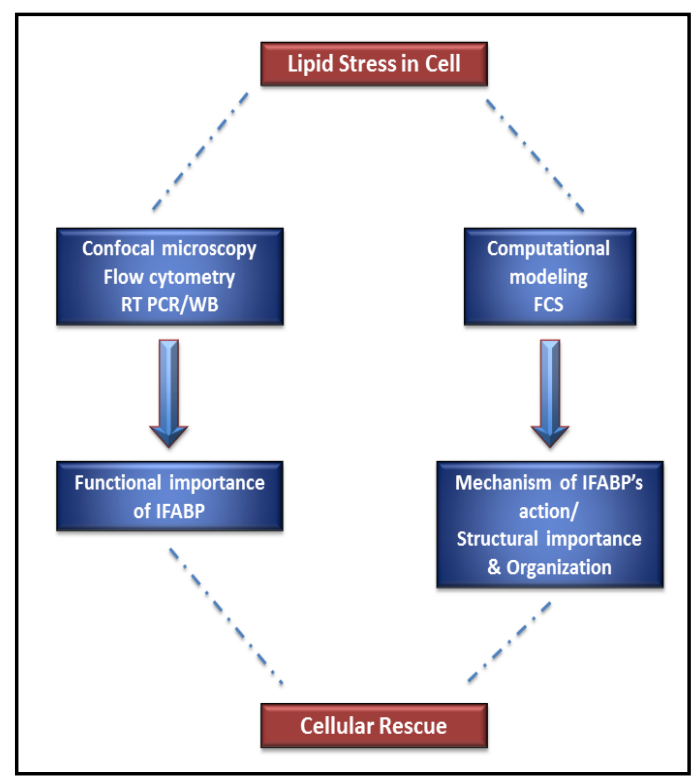

Fig. 1. Schematic Representation of the strategy adopted. 


\section{Cellular Physiology Cell Physiol Biochem 2018;51:1658-1678

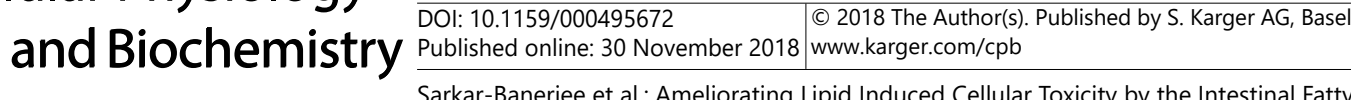 \\ Acid Binding Protein}

schematic display of the overall experimental approach in evaluating the molecular basis of IFABP's action while protecting ligand-induced stressed cells. To have a comprehensive understanding of the molecular basis of IFABP we used an ensemble approach in our investigation. This ranged from studies with cell-lines to in cell spectroscopy and molecular docking coupled with centrality analysis to unveil residue wise contribution towards internal dynamics. We have chosen mitochondria for our study for several reasons. Mitochondria are dynamic intracellular organelle with constant fusion-fission of its membrane. They are the key sites of lipid metabolism. The healthy mitochondrial networks help in the distribution of various metabolites, lipids and proteins. Their fission/fusion dynamics have recently drawn attraction for their close links with energy metabolism, respiration, and impact on cristae structure and mitochondria linked cellular death [26-29]. Mitochondria is highly involved in the apoptotic processes where several events interplays, like release of caspase activators (cytochrome c), changes in electron transport system, impairment of their transmembrane potential, changes in cellular oxidation-reduction and participation of pro- and anti-apoptotic Bcl-2 family proteins. Early changes are marked by altered mitochondrial trans-membrane potential $(\Delta \psi \mathrm{m})$ under cellular oxidative stress [30-34]. Previous report suggests that a decline in $\Delta \psi \mathrm{m}$ may also cause oxidative stress, which in turn leads to cellular apoptosis [31]. All these events are detected at the early stages even before most of the cells are irreversibly en route to apoptosis suggesting that mitochondria could be a primary target during apoptosis. FABPs, on the other hand, have been shown to bind their long chain fatty acid (LCFA) ligands efficiently [35-37]. Taken together, we hypothesized that ectopically expressed IFABP would help rescue the FA overload induced stressed cells and restore the mitochondrial network integrity. A treatment of $0.5 \mathrm{mM}$ oleate (FA analogue) would generate cellular stress marked by loss of mitochondrial membrane potential, fragmentation of mitochondria and finally apoptosis. Our string of experimental results validated by the insilico computational analyses showed that ectopically expressed IFABP restored impaired mitochondrial dynamics helping in rescuing these stressed cells from apoptosis.

\section{Materials and Methods}

\section{Materials}

Primers for cloning were obtained from the International DNA Technology (Coralville, IA). All chemicals for in vitro biophysical studies were purchased from Sigma Chemical Co. (St. Louis, USA). Reagents needed for cell culture were purchased from Life Technologies (Grand Island, NY), Expression vectors were obtained from Clontech (Mountain View, CA) and shRNA plasmids were from OriGene Technologies (Rockville, MD, USA).

Sodium oleate was purchased from Sigma Chemical Co. All primary antibodies were purchased from Santa Cruz Biotechnology, Inc. (Santa Cruz, CA). Alexa Fluor-tagged secondary antibodies, BODIPY FL C16 and microscopy reagents were purchased from Molecular Probes, Inc. (Eugene, OR). Alkaline phosphatase conjugated secondary antibodies were procured from Santa Cruz and BCIP-NBT were from Merck (Darmstadt, Germany). The JC-1 kit was purchased from Cayman Chemicals (Ann Arbor, MI). DAPI, and CellLight Mitochondria-RFP were obtained from Life Technologies (Grand Island, NY).

\section{Molecular cloning of recombinant IFABP}

WT IFABP was kindly gifted by Carl Frieden, Washington University School of Med. (St. Louis). The GFP-tagged construct of IFABP was prepared by sub-cloning pET21c-IFABP construct into pEGFP-N1 (Clontech Laboratories Inc., Mountain View, CA). Xho I and BamH I (New England BioLabs, Ipswich, MA) were the 5' and 3' restriction enzymes respectively. Primers that were used are listed in Table S1 below. (For all supplemental material see www.karger.com/10.1159/000495672). shRNA mediated gene silencing was carried out using pGFP-V-RS vector. 


\section{Cellular Physiology Cell Physiol Biochem 2018;51:1658-1678

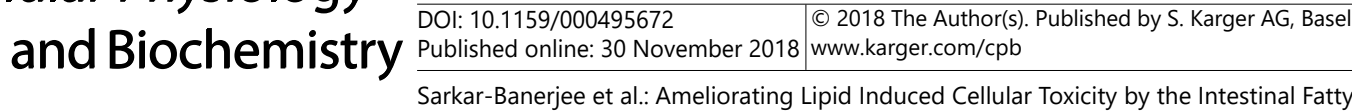 \\ Acid Binding Protein}

\section{Cell culture}

HeLa and Caco-2 cell lines were acquired from the national cell repository (National Centre for Cell Science, Pune, India). Cells were maintained in DMEM supplemented with $10 \%$ and $20 \%$ heat-inactivated Fetal Bovine Serum (FBS) respectively, $4.5 \mathrm{~g} / \mathrm{L}$ of glucose, $1.5 \mathrm{~g} / \mathrm{L}$ sodium bicarbonate, $110 \mathrm{mg} / \mathrm{L}$ sodium pyruvate, $4 \mathrm{mM}$ L-glutamine, 50 units $/ \mathrm{ml}$ penicillin G, and $50 \mu \mathrm{g} / \mathrm{ml}$ streptomycin in humidified air containing $5 \% \mathrm{CO}_{2}$ at $37^{\circ} \mathrm{C}$. Sub-culturing was achieved by passaging the cells as per ATCC recommendations (ATCC, Manassus, VA, USA). Cells were cultured in both serum and antibiotic free culture medium before each experiment.

\section{Transfection}

Cells were transiently transfected with WT or mutant IFABP DNAs using Lipofectamine LTX and Plus Reagent (Invitrogen, Carlsbad, CA) as per manufacturer's protocol. 2-2.5 $\mu \mathrm{g}$ of DNA/35mm dish were used for transfection. Gene expression was assessed after 72-96 hours (for knockdown studies) or after 48 hours (for all others). Generation of stable cell lines were carried out as described elsewhere [38].

\section{Treatments}

Cells were serum starved for 18-24 hours before treatment. Sodium oleate was chosen as the free FA in all our experiments described here. Sodium oleate was prepared by dissolving in methanol to a final concentration of $50 \mathrm{mM}$ and was diluted in incomplete medium to a final concentration of 0.3 or $0.5 \mathrm{mM}$ as and when required for experiments [39]. Oleate treatments were continued for 6-8 hours [39] before any downstream experiments. In all experiments, desired control groups received comparable volume of vehicles as treated groups. BODIPY FL C16 was added as $1 \mu \mathrm{M}$ for $30 \mathrm{mins}$ at $37^{\circ} \mathrm{C}$ as mentioned elsewhere [20].

\section{Mitochondrial staining}

Cells transfected with wild type IFABP-GFPconstructs were transduced with CellLight MitochondriaRFP (Molecular Probes Inc., Eugene, OR, USA) as described elsewhere [40], washed with 1X DPBS and imaged using the imaging medium (20 mM HEPES, $150 \mathrm{mM} \mathrm{NaCl}, 5 \mathrm{mM} \mathrm{KCl}, 1 \mathrm{mM} \mathrm{CaCl}_{2}, 1 \mathrm{mM} \mathrm{MgCl}$, $\mathrm{pH} 7.4$ along with $1 \%$ glucose) for studying mitochondrial dynamics. For JC-1 staining, cells were stained using the JC-1 Mitochondrial Membrane Potential Assay Kit according to manufacturer's protocol (Cayman chemical, Ann Arbor, MI,).

\section{Western blotting}

Cells were lysed using CelLytic MT lysis buffer (Sigma Aldrich) along with the protease and phosphatase inhibitor cocktail as described elsewhere [41]. Proteins obtained were quantified using BCA reagent (Pierce). 80-100 $\mu$ g for HeLa whole cell lysate and 100-120ug for Caco2 whole cell lysate from each experimental group were loaded into each well of $12.5 \%$ SDS-PAGE. Western blot transfer was performed in a semi-dry transfer apparatus Trans-Blot SD (BIORAD). Western immunoblots were developed using BCIP/ NBT (Merck) substrates against alkaline phosphatase tagged secondary antibodies.

\section{Microscopy}

Cells cultured in $35 \mathrm{~mm}$ glass bottom dishes (MatTek Corporation, Ashland, MA, USA) were used for live cell imaging. All live cell imaging were performed by immersing cells in imaging medium $(20 \mathrm{mM}$ HEPES, $150 \mathrm{mM} \mathrm{NaCl}, 5 \mathrm{mM} \mathrm{KCl}, 1 \mathrm{mM} \mathrm{CaCl}, 1 \mathrm{mM} \mathrm{MgCl}$, $\mathrm{pH} 7.4$ along with $1 \%$ glucose) [42], which were kept inside a stage top incubator with $\mathrm{CO}_{2}$ control set-up. Cells were imaged with a LSM510 Meta confocal microscope (Zeiss). For the imaging, Plan-Apochromat 63X/1.40 N.A. oil objective was used for acquiring images with 512 X512 pixel frame size and pinhole aperture size of $\sim 1$ airy unit. EGFP and its fusion proteins were excited using the 488-nm line of an argon-ion laser (Lasos, Jena, Germany) and the emission was detected using a $500-530 \mathrm{~nm}$ band pass filter. Mitochondrial dynamics were studied by exciting CellLight Mito-RFP using the 561-nm DPSS laser and the emission was captured using a $575 \mathrm{~nm}$ long pass filter. Live cell mitochondrial dynamics were imaged as described elsewhere [43]. Time lapse between the frames 


\section{Cellular Physiology Cell Physiol Biochem 2018;51:1658-1678

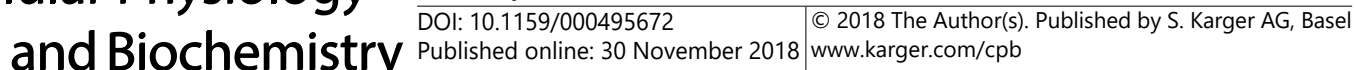

Sarkar-Banerjee et al.: Ameliorating Lipid Induced Cellular Toxicity by the Intestinal Fatty

Acid Binding Protein

was $10 \mathrm{sec}$. Mitochondrial membrane potential was imaged by using JC-1 stain according to manufacturer's protocol (Cayman Chemical Company, Ann Arbor, MI, USA). All nuclear counter-staining with Hoechst 33342 (for live cells) were imaged by excitation with $405 \mathrm{~nm}$ Diode laser and detected using a 420-480 $\mathrm{nm}$ band pass filter. Unidirectional scanning with speed set to 4 or 5 was used. Pixel dimensions and step sizes were set according to Nyquist sampling criteria for confocal microscopy (Pawley, 2006). Identical detector gain, offset, pinhole aperture, laser power and stack parameters were standardized for images acquisitions. Wide field fluorescence microscopy was performed using Olympus BX 51 upright (Olympus, Tokyo, Japan). Standard DAPI filter set (for imaging fixed cells counter-stained with DAPI) and arc lamp illumination were used for these measurements. Wide field fluorescence was captured using SONY Color Video Camera ExwaveHAD.

\section{Quantitative real-time PCR}

Total RNA was isolated from cell lines using TRI-reagent (Sigma) following the standard protocol succeeded by cDNA synthesis from $1 \mu \mathrm{g}$ RNA using iScript (Fermentas, Cleveland, OH, USA). Q-PCR was performed with fluorescent Power SYBR Green-I on the ABI 7500 Real-Time PCR system (Applied Biosystems, Foster City, CA). 18s levels were used as loading control. The primers used were as follows: human 18s forward 5'-GATTCCGTGGGTGGTGGTGC-3' and reverse 5'-AAGAAGTTGGGGGACGCCGA-3', IFABP forward - 5ACTGACGATCACACAGGAAGGA-3' and reverse - 5'-GCCGAGTTCAAACACAACATCA-3'.

\section{Flow Cytometry}

FITC-Annexin-V staining was used to determine the effect of oleate treatment on HeLa cells with and without transient IFABP expression by 'Apoptosis kit' (Molecular Probes) as per manufacturer's protocol. Percentages of cells positive for Annexin-V and PI individually or in combination were detected by flow cytometry and the dot blot analysis was done using Cell Quest Pro software (BD Biosciences, San Jose, CA, USA). Effect of oleate treatment was probed for $8 \mathrm{hrs}$. A separate set with transiently IFABP transfected cells was also subjected to apoptosis assay to investigate any possible impact of transient IFABP expression.

\section{Diffusional dynamics of IFABP as studied by FCS}

FCS measurements of the IFABP- transfected HeLa cells were carried out using a Zeiss 510 META Confocor3 LSM set-up (Carl Zeiss, Evotech, Jena, Germany) in live cells as described elsewhere [44]. C-Apochromat 40X/1.2 N.A. water immersion objective was used for these studies. Briefly, cells were cultured in Lab-Tek II chambered coverglass (Nunc, Roskilde, Denmark) and imaged by routine CLSM methods. Specific region of interests (ROIs) were selected according to the experimental needs and FCS experiments were carried out at the selected ROIs. Typically, 10 acquisitions for 10 seconds each were carried out at the individual ROIs. 10-15 such sets of measurements were typically used. Autocorrelations were determined from a collection of three independent sets of experiments. From the fits of the correlation functions, the values of diffusion time $\left(\tau_{D}\right)$ and diffusion coefficients (D) were obtained (see equations 2, 3 and 5 in Supplementary Materials). For the calculation of $\omega$, the diffusion coefficient of free EGFP was considered. D of EGFP in HeLa cell cytoplasm was found to be $D_{\text {EGFP }}=24 \mu \mathrm{m}^{2} \mathrm{sec}^{-1}$ which is similar to what was previously obtained [45]. Our FCS data were fitted using OriginPro data analysis software and has been described in details in the Supplementary Materials. Our experimental data sets were typically fitted to anomalous two diffusion fitting model considering the cellular compartments to be crowded and a single diffusion fit would not suffice for the free as well as restricted diffusing proteins inside the cell cytoplasm.

\section{Molecular docking}

To have a mechanistic insight into the ligand induced cluster dissociation as was evident from our FCS finding, we resorted to theoretical approaches. We went on to have the docking output by resorting to molecular docking. The co-ordinate information of IFABP was obtained from the Protein Data Bank (PDB) (PDB ID: 1IFB). The energy structure of oleate and palmitate was minimized using the Avogadro 1.1.1 molecular editor and the MOL2 format was used as the ligand input for docking analysis. Water molecules and all bound ligand molecules were removed from the downloaded PDB file of IFABP using the DockPrep plugin of UCSF Chimera molecular viewer. Polar hydrogen atoms and Gasteiger charges were added to the IFABP crystal structure before starting the docking process. Protein-ligand docking was carried out with SwissDock, which relies on the back-end software EADock DSS in CHARMM force field. The lowest binding 


\section{Cellular Physiology Cell Physiol Biochem 2018;51:1658-1678

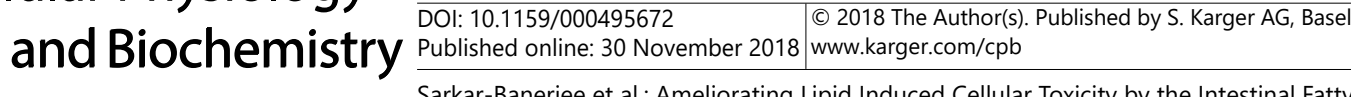 \\ Acid Binding Protein}

energy was chosen from among the most possible 10 top order docking conformations. The result was analyzed by DockView plugin of UCSF Chimera.

For the protein-protein docking, tools from ClusPro were used [46]. Homo-multimers of IFABP were allowed to dock with one another. The topmost docking output defined by centers of highly populated clusters of low-energy docked structures was highlighted for our subsequent analysis.

\section{Betweenness Centrality Calculation}

With the objective to understand the stretches which contribute maximally to the conformational dynamics of IFABP in case of various FAs like oleate bound, palmitate bound along with the unbound state we went ahead to generate the centrality plots by an assessment of betweenness centrality of the PDB coordinate inputs. PDB entries 1IFB, 2IFB and 1ICN were used for co-ordinate information of unbound as well as palmitate and oleate bound IFABP respectively. Calculating network node centrality and suboptimal paths through the network involves a network analysis of the co-ordinate files.

Node centrality depicts the distribution of the edges in the network. In protein-networks, identification of nodes with many edges (hubs) as well as the segments with a high number of connections provides an insight into the internal dynamic coordination of protein regions. Centrality measures can also be deployed to characterize protein sections showing differences in coupled motions between networks derived from different states (e.g. ligand bound and unbound etc.).

The betweenness centrality of a node is the number of unique-shortest paths crossing that node. This measure has the advantage of considering the whole network topology and not only the closest neighbors in its calculation (as is the case with node degree). The igraph package of Bio3D was used to perform the calculation of degree, betweenness and closeness. All statistical calculations were done on the R-platform.

\section{Image and data analysis}

Images were analyzed using ImageJ software (NIH, Bethesda, Maryland, USA). Image stacks were converted into maximum intensity projections and average intensity projections for the display and quantification processes, respectively.

\section{Statistical analysis}

All experiments were performed at least three times and representative data are shown. Statistical calculations were performed using Origin 8 (OriginLab Corp., Northampton, MA, USA). Experimental values were expressed as means \pm SEM of at least three independent measurements unless stated otherwise. Unpaired, two-tailed Student's $t$ test was used to compare means and $P<0.05$ was considered as statistically significant.

\section{Results}

\section{Fatty acid overload induces cellular toxicity}

In our current study, we resorted to two different cell lines viz. human cervical HeLa cells (surrogate system for the ectopic expression of IFABP) and the human intestinal epithelial Caco-2 cells (natively expressing IFABP). $0.5 \mathrm{mM}$ oleate has been shown earlier to upregulate IFABP expression [25]. High oleate concentration has been detrimental to the cells and $0.6 \mathrm{mM}$ oleate is known to inhibit T-lymphocyte proliferation [34]. We treated our cells with sodium oleate, which was chosen to be the ligand for IFABP $[47,48]$. Treatment with $0.5 \mathrm{mM}$ concentrations of oleate induced apoptosis in HeLa and Caco- 2 cells, as scored by Hoechst33342 staining for condensed nuclear morphologies (Fig. 2A and 2B). Apoptosis was induced in HeLa cells at an intermediate concentration as low as $0.3 \mathrm{mM}$. The response for the HeLa cells increased significantly in groups treated with $0.5 \mathrm{mM}$ of oleate (Fig. 2A and 2C) (marked by white arrows in Fig. 2A). On the contrary, we found that the extent of apoptotic cell death was less in Caco-2 cells (75\%) compared to that in HeLa cells (90\%) (Fig. 2B and 2D). This can be explained by the fact that HeLa cells do not express IFABP, whereas the basal level expression of IFABP in wild type Caco-2 cells could combat the adverse effects of FA levels by neutralizing excess FAs. Positive control groups in this case were treated with 


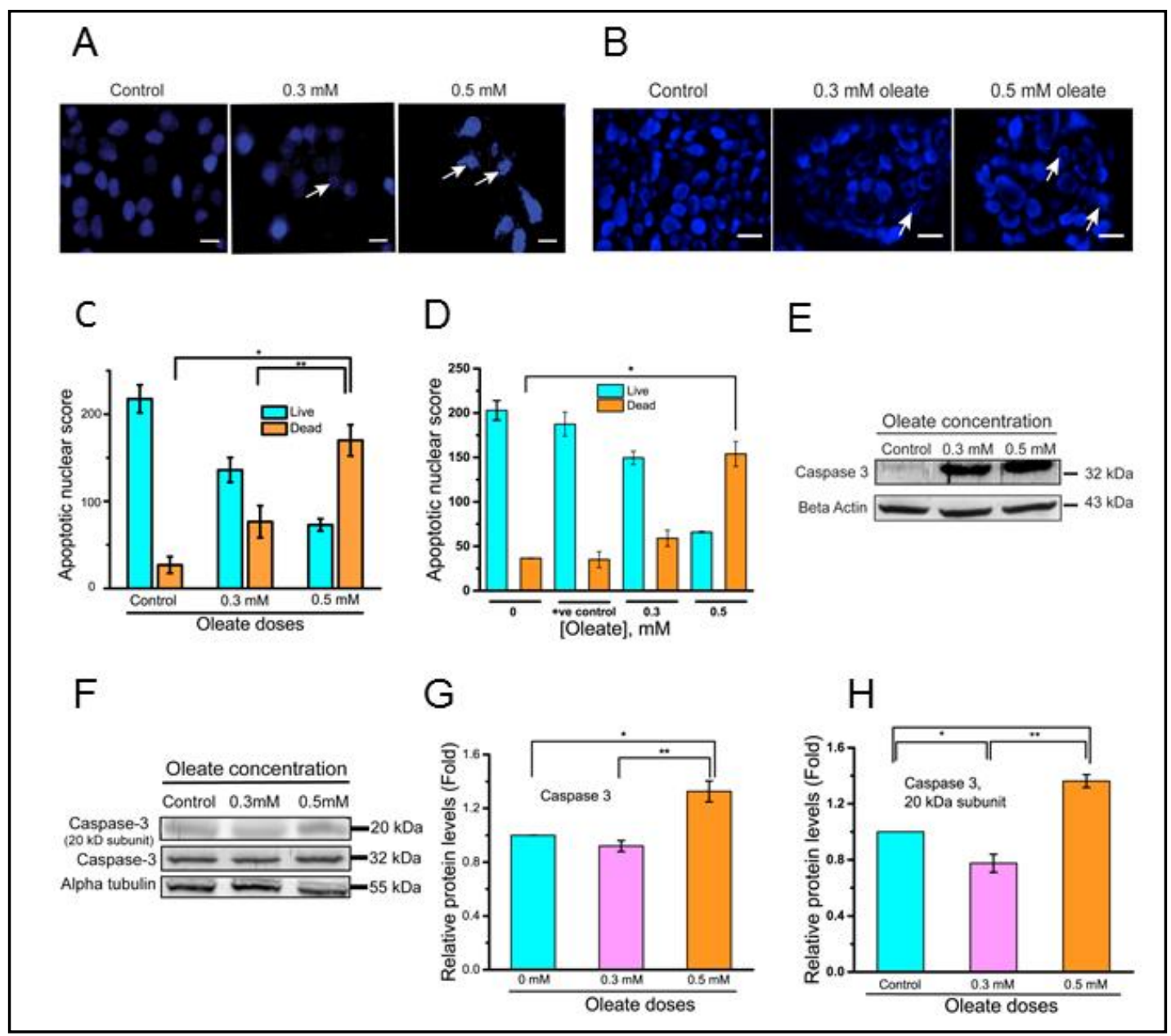

Fig. 2. Induction of lipid toxicity in HeLa and Caco-2 cells. (A) Induction of apoptosis with increasing dose of fatty acid (FA) ligand in WT HeLa and (B) Caco-2 cells as observed by fragmented nuclei stained with Hoechst 33342. The apoptotic nuclei are marked by white arrow. Scale bar $25 \mu \mathrm{m}$. (C) and (D) Apoptotic nuclear count increases as oleate concentration rises. (E) Caspase 3 subunit protein expression by western blot showed that increasing the dose of FA ligand, apoptosis commences with the release of pro-apoptotic markers like caspase 3. (F) The expression of Caspase-3 and cleaved Caspase-3 is studied by western blot. ( $G$ and $H$ ) the expression of Caspase 3 and its $20 \mathrm{kDa}$ subunit increase showing the onset of apoptosis. It was observed that the expression of both Caspase 3 and its $20 \mathrm{kDa}$ subunit increased profoundly at $0.5 \mathrm{mM}$ concentration of FA. Values represent means \pm SEM of $n=3$ experiments, ${ }^{* *} \mathrm{P}<0.01,{ }^{*} \mathrm{P}<0.05$.

salt/ion balanced buffer. With increasing oleate concentration, apoptotic nuclear score significantly increased over the control (Fig. 2C and 2D). Induction of apoptosis in HeLa cells was also probed by increased expression of caspase-3, which is known to be a pro-apoptotic marker (Fig. 2E). Uptake of FAs in CaCo-2 cells was confirmed by treating them with BODIPY FL- $\mathrm{C}_{16}$, a fluorescently labeled FA analog (Fig. S1). Apoptotic protein markers like caspase 3 $(32 \mathrm{kD})$ and its subunit $(20 \mathrm{kD})$ were increased in the FA treated CaCo-2 cells (Fig. 2F, 2G and $2 \mathrm{H}$ ). The results suggested that oleate mediated fatty acid overload induced apoptosis not only in HeLa cells but also in Caco-2 cells, albeit to a lesser extent with respect to the changes in their nuclear morphology. 


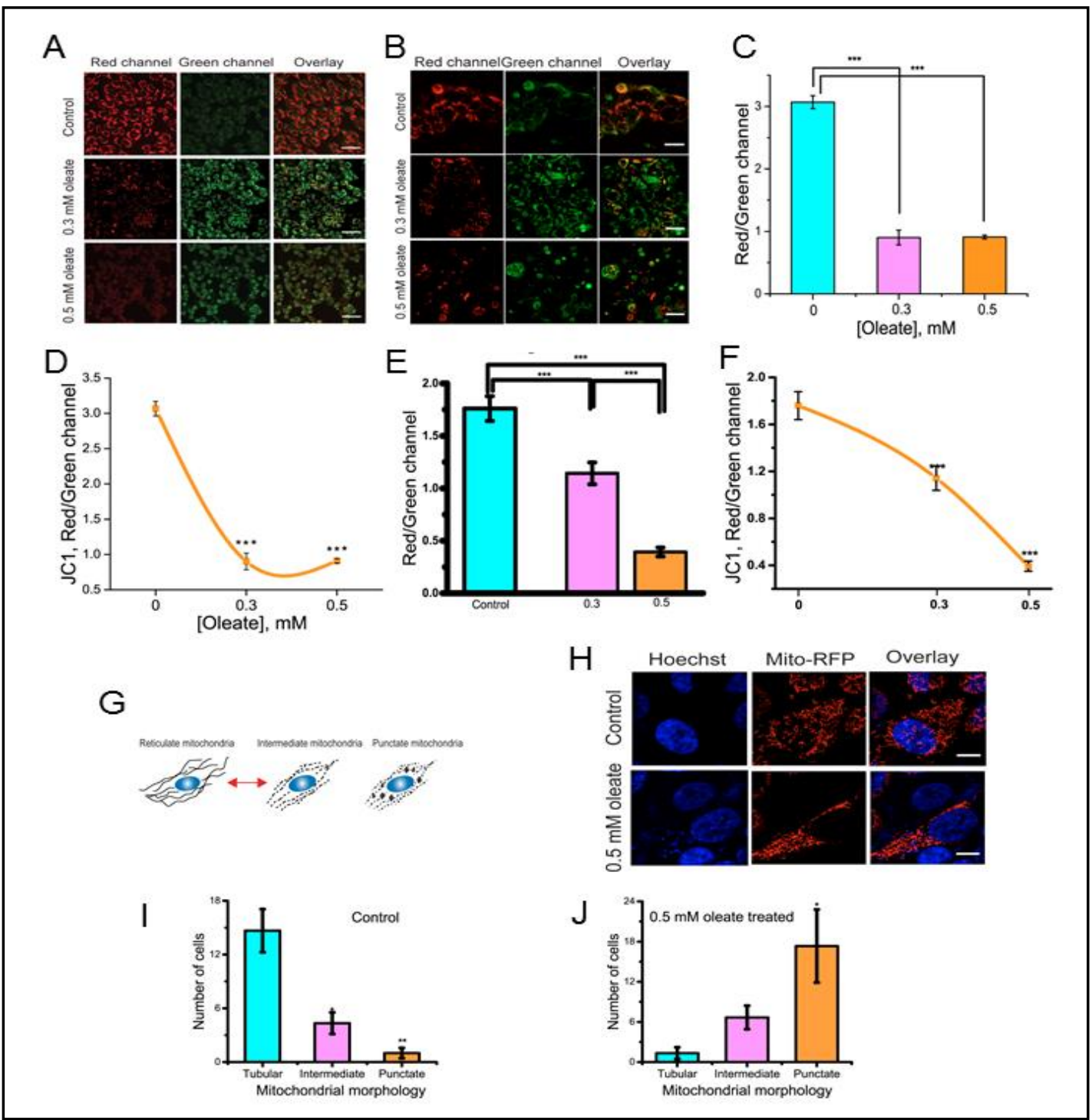

Fig. 3. Loss of mitochondrial membrane potential and integrity under fatty acid induced cell toxicity. (A) JC1 staining of WT HeLa cells upon treatment with increasing FA ligand revealed loss of mitochondrial membrane potential $(\Delta \psi \mathrm{m})$. This loss in $\Delta \psi \mathrm{m}$ was visible by reduction in the formation of JC1- aggregates (red) and deposition of J1 monomers (green). Scale bar $50 \mu \mathrm{m}$. (B) JC1 staining of Caco-2 cells showing loss of mitochondrial membrane potential with increase in FA concentrations. Scale bar $50 \mu \mathrm{m}$. (C) The change in $\Delta \psi \mathrm{m}$ of HeLa cells was quantified by the marked reduction in red/green channel signal in fluorescence microscope. With decrease in JC1 aggregates (red in color), the red vs. green ratio decrease, indicating a loss of membrane potential of mitochondria. (D) The line drawn to show the trend of decrease in red/green channel for HeLa cells. (E) The ratio of red/green fluorescence for Caco-2 cells decreased with increase in lipid toxicity. (F) The decrease in mitochondrial membrane potential is a slow process in Caco-2 cells. (G) Pictorial representation showing inter-conversion of tubular and intermediate mitochondria and formation of fragmented structures. (H) Live cell confocal microscopy of wild type HeLa cells revealed changes in mitochondrial morphology with occurrence of fragmented or punctate characteristics in oleate treated cells over the tubular networks of control cells. Scale bar $10 \mu \mathrm{m}$. (I and J) Quantification of change in mitochondrial morphology across control and oleate treated wild type HeLa cells respectively. Values represent means \pm SEM of $\mathrm{n}=3$ experiments, ${ }^{* *} \mathrm{P}<0.01,{ }^{*} \mathrm{P}<0.05$. 


\section{Cellular Physiology Cell Physiol Biochem 2018;51:1658-1678 \\ and Biochemistry \begin{tabular}{l|l} 
Published online: 30 November 2018 & $\begin{array}{l}\text { @ } 2018 \text { The Author(s). Published by S. Karger AG, Basel } \\
\text { www.karger.com/cpb }\end{array}$ \\
\hline Sarkar-Banerjee et al.: Ameliorating Lipid Induced Cellular Toxicity by the Intestinal Fatty
\end{tabular} \\ Acid Binding Protein}

\section{Fatty acid overload impairs mitochondrial dynamics}

Treatment with $0.5 \mathrm{mM}$ oleate induced apoptotic responses and was used as the experimental dose in subsequent studies. FA induced changes in mitochondrial membrane potential was observed by JC1 staining in both HeLa (Fig. 3A) and Caco-2 cells (Fig. 3B). The ratio between the red and green channels in confocal images of the JC- 1 stained HeLa cells showed a decreasing trend (Fig. 3C and 3D) with increased loss of mitochondrial membrane potential $\left(\Delta \psi_{\mathrm{m}}\right)$ and abundant deposition of green JC-1 monomers. Similar result was obtained in Caco-2 cells (Fig. 3E and 3F), although the effect was milder as evidenced by the gradual decrease in signal in contrast to the sharp decrease in HeLa cells (Fig. 3C and 3D). Changes in the mitochondrial morphology were also studied in HeLa cells under FA overload, using live cell confocal imaging. Control cells were characterized by the presence of long, filamentous/ reticulate mitochondria which were in dynamic equilibrium with their intermediate structures (Fig. 3G), a phenomenon that takes place by the fission-fusion mechanism (Fig. 3H). Such morphometric phenotypes have been used earlier to differentiate FA overload induced cells [49].

Tubular mitochondrial network in our control HeLa cells was in sharp contrast to the increased number of fragmented mitochondria observed for the oleate treated samples (Fig. 3I and 3J). The fusion/fission dynamics in mitochondrial morphology was also evident in the time lapse imaging of the live cells.

IFABP partially rescues HeLa cells from FA overload induced apoptosis and mitochondrial depotentiation

Oleate treated cells showed up-regulated pro-apoptoticgene bax, while ectopic expression of IFABP (both in presence or absence of oleate) down-regulated it with concomitant upregulation of the anti-apoptotic gene bcl2 (Fig. 4A). This observation implicates the role of IFABP in rescuing cells from fatty acid induced cell stress. Cellular apoptosis was quantified using Annexin-V (FITC-A channel) and propidium iodide, PI (PE Texas Red A channel) staining in HeLa cells. A decrease in the Annexin- $V$ positive population from $52 \%$ (in cells without transient IFABP expression) to $36 \%$ (in cells with transient IFABP expression) was observed under conditions of oleate treatment (Fig. 4B and 4C). Furthermore, transient IFABP expression rescued the lipid stressed cells from early apoptosis by $12 \%$ as compared to the cells without IFABP expression. IFABP-transfected cells reflected comparable viable population with respect to control cells (without transfection). This was also evident from the reduced apoptotic nuclear count in the HeLa cells ectopically expressing IFABP (Fig. 4D and $4 \mathrm{E})$. Cells ectopically expressing IFABP were also protected from mitochondrial impairment under FA stress (Fig. 4F). Apart from the above findings, mitochondrial morphology in Caco2 cells ectopically expressing IFABP-GFP retained its reticulate structures significantly even after FA treatment (Fig. 4G) suggesting that IFABP partially helps restoring the morphological dynamics of mitochondria under FA overload. Apoptotic nuclear count was also considerably low in these cells (Fig. 4H). As a whole, the above results portray the effectiveness of IFABP in conserving mitochondrial morphologies and cell viability, at least partially, surpassing the harsh environment of FAs overload induced apoptosis.

Mitochondrial morphologies were compromised under metabolic stress in IFABP knockdown Caco-2 cells

To assess the functional relevance of IFABP and to justify its importance in modulating mitochondrial dynamics, IFABP gene was knocked down in Caco-2 cells (Fig. 5A). These cells were then treated with $0.5 \mathrm{mM}$ of FA, which resulted in degeneration of mitochondrial morphology and formation of punctate or fragmented structures (Fig. 5B). Not only that, Caco2 cells lacking IFABP were less protected from the FA induced stress (Fig. 5C). Thus, absence of IFABP in Caco- 2 cells rendered the cells more vulnerable to oleate induced deformation of mitochondrial morphologies and onset of apoptosis. These results strengthens IFABP's role as an important candidate in the regulation of cellular health under metabolic stress caused by FA overload. 


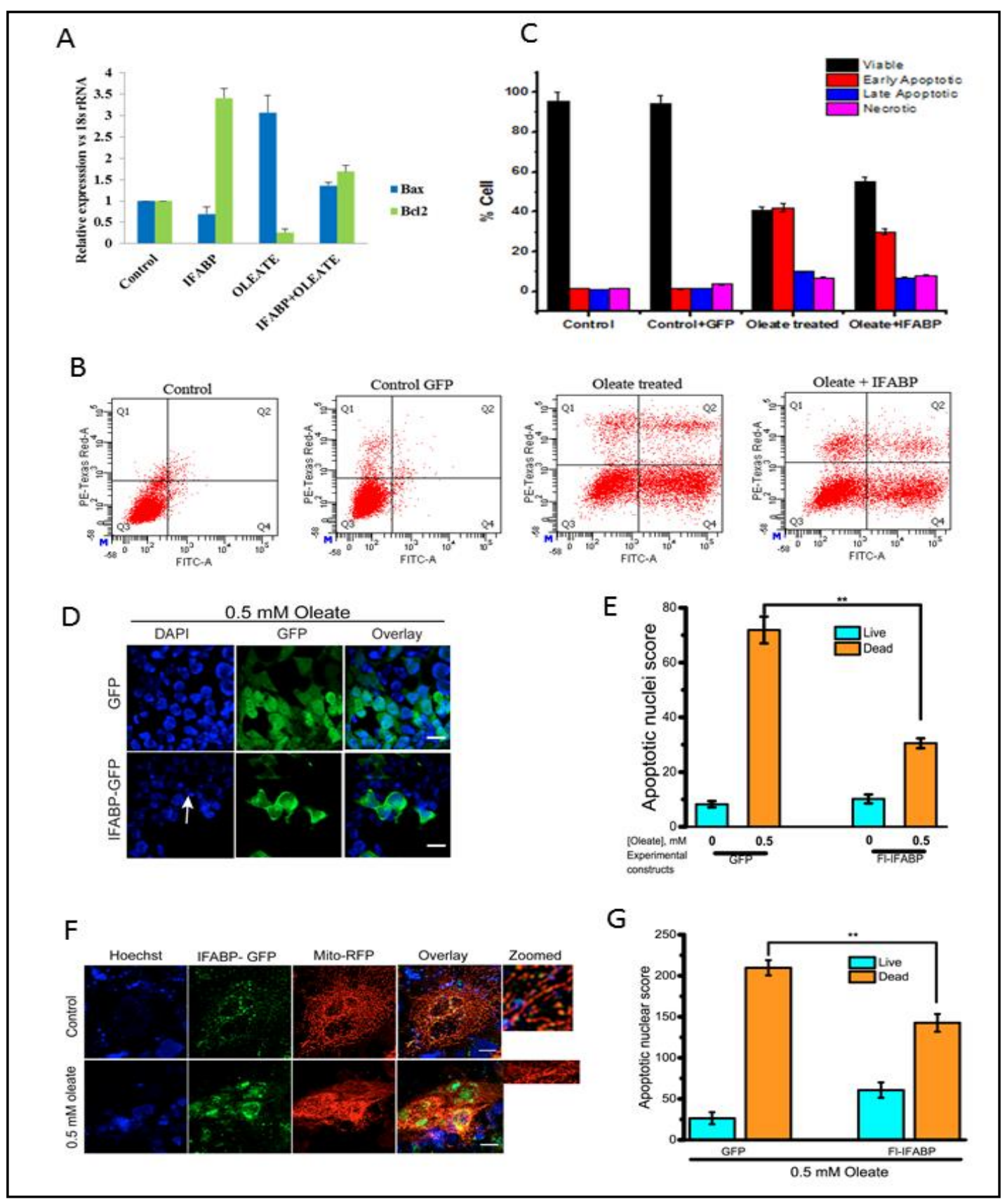

Fig. 4. (A) q-PCR result showing up-regulation of the pro-apoptotic gene bax in cells with lipid stress. IFABP overexpression on the other hand in lipid stressed state led to its down regulation with concomitant up-regulation of the anti-apoptotic gene bcl2 (B) FACS readout using Annexin-V (FITC-A channel) and propidium iodide (PE Texas Red A channel) stained population reflecting early (Q4) and late apoptotic cell populations (Q2). (C) Histogram depicting a drop in the Annexin- V positive population in cells with transient IFABP expression under conditions of oleate treatment. (D) Effect of high dose of FA ligand on the nuclear morphology of IFABP expressing cells over the GFP (or, vehicle) transfected cells, scale bar 20 $\mu \mathrm{m}$. (E) Bar graph representing the effect of excess FAs on the WT IFABP transfected HeLa cells. It was observed that the WT IFABPs was efficient to reduce the lipotoxic effect on apoptosis. Values represent means \pm SEM of $n=3$ experiments, ${ }^{* *} \mathrm{P}<0.01,{ }^{*} \mathrm{P}<0.05$. (F) Caco- 2 cells transfected with IFABP-GFP was found to protect the mitochondrial morphology in high FA concentrations in the cells, scale bar $50 \mu \mathrm{m}$. (G) Bar graph representing the effect of excess FAs on the WT IFABP transfected Caco-2 cells. Values represent means \pm SEM of $\mathrm{n}=3$ experiments, ${ }^{* * *} \mathrm{P}<0.001,{ }^{* *} \mathrm{P}<0.01,{ }^{*} \mathrm{P}<0.05$. 
Sarkar-Banerjee et al.: Ameliorating Lipid Induced Cellular Toxicity by the Intestinal Fatty Acid Binding Protein

Fig. 5. Caco-2 cells lacking IFABP are not protected from apoptosis and loss of mitochondrial dynamics. (A) Knockdown of IFABP expression in Caco-2 cells; Scr, scramble. (B) shRNA mediated knockdown of IFABP in Caco-2 cells which could not protect the mitochondrial morphology inside the cells at high FA concentrations, which was observed with fragmented mitochondria, scale bar 10 $\mu \mathrm{m}$. (C) Caco 2 cells lacking IFABP were less protected from the FA induced stress.

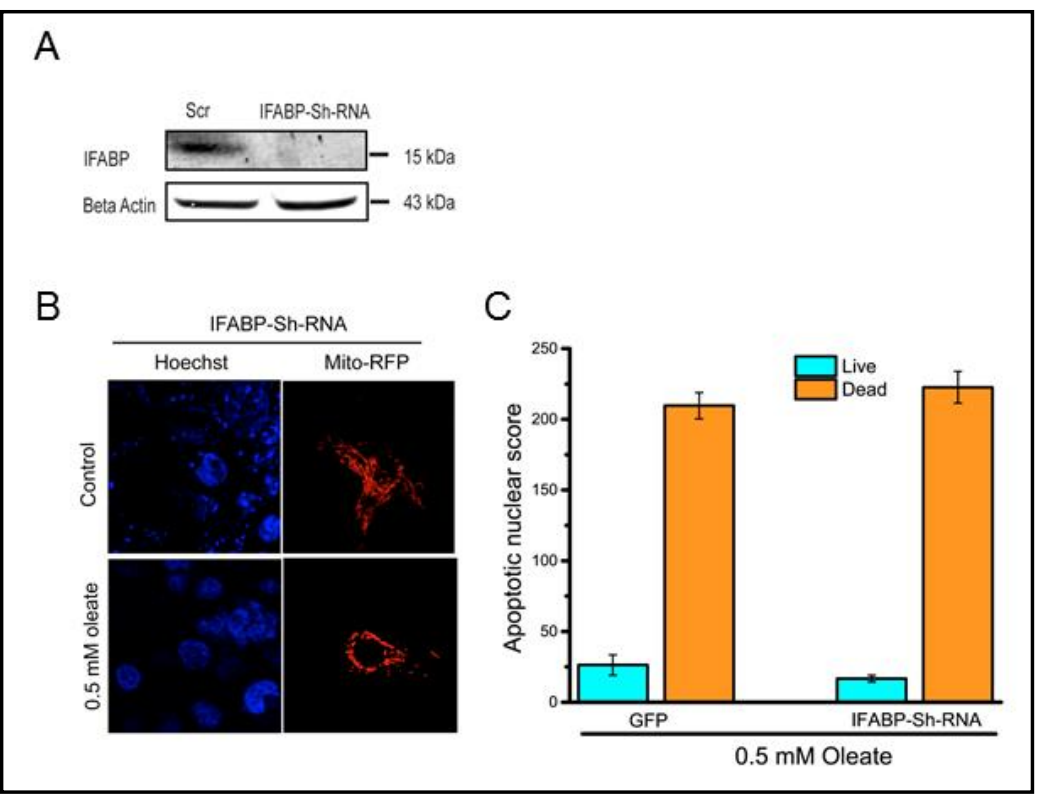

FA deprivation leads to self-association and cluster formation of IFABP

To address the structure-function relationship of IFABP, we have studied the diffusional dynamics of IFABP-GFP in live cells using fluorescence correlation spectroscopy (FCS) (Fig. 6A). In absence of FA, the ligand-free unbound IFABPs were found to form self-associated clusters. These clusters were mostly abundant around the nucleus as well as in the cytoplasm and were dynamic in nature. Since the protein is synthesized in the ER, shuttles through the Golgi and ferries FAs to organelles concentrated in the perinuclear space, such localization pattern was obvious and complies with the general localization pattern of IFABP which is predominantly cytosolic. Such clusters continuously ferry between the cell membrane and the juxta-nuclear region. We performed FCS at the marked regions of interest (ROI) (Fig. 6A) to study the diffusional characteristics of both the soluble (position 1) and clustered (position 2) states of the protein in the absence of ligand. Autocorrelation curves (Fig. 6B) obtained from FCS measurements at these two different ROIs were fit to two different fitting models: the cytoplasmic proteins (marked position 1) were fit successfully using a single component diffusion model. The suitability of the single diffusion component model was determined using the randomness of the residual distribution (Fig. 6C). Force-fitting the data to an anomalous diffusion model resulted in a fit with the $\mathrm{d}_{w}$ of 2.03 , which effectively means that the use of one component diffusion model is sufficient for the present analysis [50]. The diffusion coefficient (D) of these free cytoplasmic proteins was found to be around $8.3 \pm 0.1 \mu \mathrm{m}^{2} \mathrm{sec}^{-1}$ (point 1 in Fig. 6B); whereas the clusters were fit to a sum of two diffusion components and the diffusion coefficients were found to be around $3.3 \pm 0.3 \mu \mathrm{m}^{2} \mathrm{sec}^{-1}$ (for the fast-moving components, point 2 in Fig. 6B) and $0.8 \pm 1.1 \mu^{2} \mathrm{sec}^{-1}$ (for the slow-moving components, point 2 in Fig. 6B). The goodness of the fits was verified by the randomness of the residual distribution (Fig. 6C). It was interesting to note that the spatial distribution of these clusters changed with the availability of lipid ligands and the proteins localized diffusely in the cell cytoplasm (Fig. 6D). There were no or very low traces of clusters with the availability of the FA ligand (Fig. 6D). Quantification of the number of proteins in the clusters was beyond our scope of experiment and hence not shown. The high amplitudes from the autocorrelation data $\mathrm{G}(0)$ correlates with low $\mathrm{N}$-number (number of particles) for the protein clusters (Fig. $6 \mathrm{~B})$. The inverse relation between $\mathrm{G}(0)$ and $\mathrm{N}$ has been shown in previous reports (20). This observation suggested the possibility of the presence of heterogeneous species (possibly larger oligomers) in the clusters. Fig. $6 \mathrm{E}$ represents the variation of intensity across the free diffused species and the clustered species inside the HeLa cells whereas Fig. 6F and Fig. 6G 


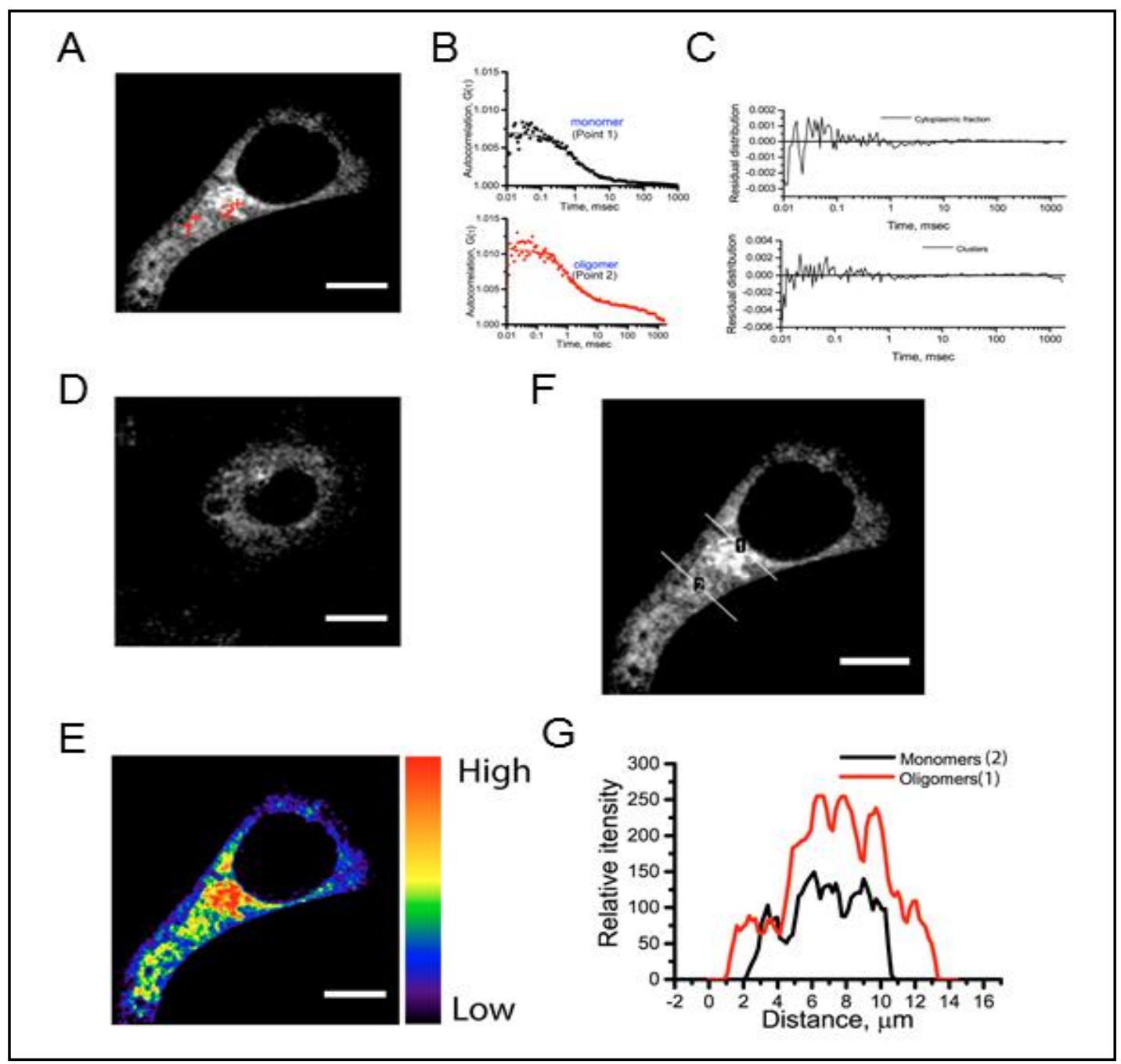

Fig. 6. Different localization pattern of IFABP with availability of fatty acid ligand. (A) Confocal image of wild type IFABP-EGFP transfected HeLa cell showing the diffused cytoplasmic and perinuclear clusters of IFABP. Scale bar $10 \mu \mathrm{m}$. (B) Autocorrelation functions of the diffused and clustered species of IFABP in HeLa cell; the solid lines along the scattered plots represent the fit. (C) Residual distributions of the autocorrelation functions of the diffused and clustered IFABP showing the goodness of the fit. (D) Replenishment of the HeLa cells with FA shows very few or visibly no cluster formations of IFABP. (E) Intensity color map showing the distribution of the high density population of IFABP clusters in HeLa cells in the absence of the FA ligand. (F) The HeLa cell showing the distribution of the higher density oligomers and the free monomers in the cytosol. (G) The intensity distribution plot of the diffused and clustered IFABP along the drawn line in the HeLa cells showed that the clusters had higher intensity than the diffused particles.

show the intensity distribution along a line (of identical length) drawn across the clusters (position 1) and the cytoplasm (position 2). The clusters had relatively brighter intensity than the free cytosolic species that were shown by our confocal and FCS results (Table S2).

\section{Ligand Induced Dissociation of IFABP clusters as probed by in-silico study}

According to SwissDock outputs involving an array of backend analysis and an estimation of CHARMM energies on a grid, IFABP was observed to have a cleft which accommodates oleate in several possible orientations (Fig. 7A-D). This analysis can be extremely effective in terms of ligand binding and the local dynamics associated with the binding [51]. The

\section{KARGER}


Sarkar-Banerjee et al.: Ameliorating Lipid Induced Cellular Toxicity by the Intestinal Fatty Acid Binding Protein

Fig. 7. (A) protein-protein dimer (IFABP) indicating surface overlap along with the measure of distance between residue 120 and residue 55 for both the chains. (B) Distance between residue 120 and 45, which has an impact on ligand binding. (C) IFABP tetramer assembly. (D) Oleate-bound IFABP manifests the oleate is inside the cleft. (E) Palmitate ligand positioning inside the same binding cleft in case of Palmitate-bound IFABP.

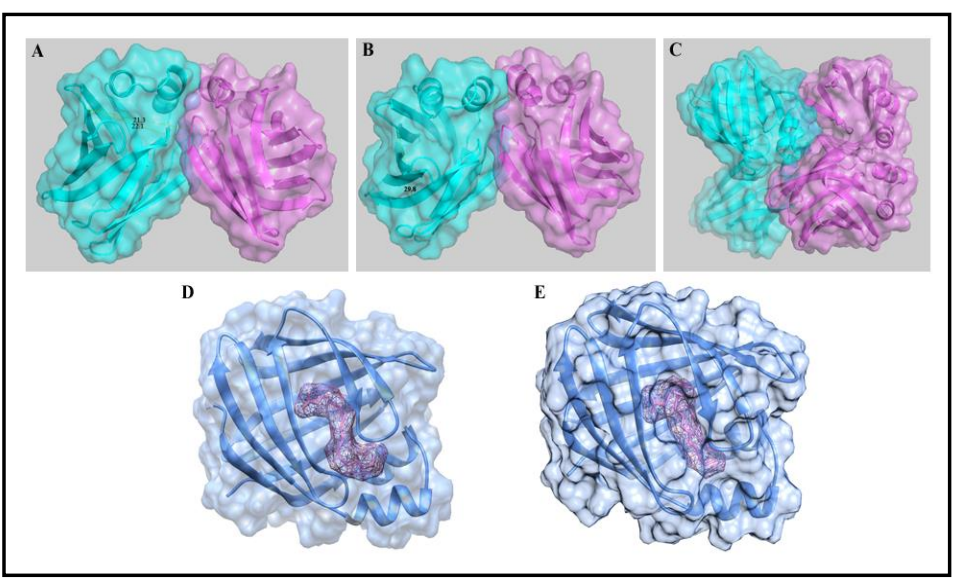

Figure here depicts an ensemble average of the top docking conformations. Previous reports suggest that residues 44,86 and 110 can be highly decisive in deciding the ligand binding [52]. Furthermore, as observed in the FCS analysis, the protein-protein docking output obtained from ClusPro tools also revealed higher order associations of IFABP monomers. The region of surface-overlaps of the dimeric and tetrameric assemblies was scoured using the DockView plugin of UCSF chimera. Residues 45 to 60 were found to be decisive in forming the monomer-monomer interface. It is very likely that owing to its close proximity to the binding cleft (residue 55 of chain A to binding cleft: $22.1 \AA$ and residue 55 of chain $\mathrm{B}$ to binding cleft: $21.3 \AA ̊$ ) (Fig. $7 \mathrm{~A}$ ) a local conformational change emanating upon ligand binding dislodges the bound monomer, thereby disrupting the higher order associations. Furthermore, the local conformational change induced upon oleate binding stands plausible as the predominant organization in region flanking the cleft and protein binding interface is helix and loop (Fig. 7D).

\section{Centrality study unveils switching of residue specific contribution to internal dynamics}

Our betweenness centrality plots (Fig. 8) revealed a significant difference in the stretch positions contributing to the internal dynamics of IFABP under ligand bound and unbound state. Region 64 to 74 was found to contribute maximally in native IFABP (Fig. 8A). While upon ligand binding the maximum contribution emanates from 54 to 60 coupled with few sporadic contributions spanning from residue 90 to 100 (Fig. 8B). On the contrary region 64 to 74 had minimal contribution to internal dynamics under oleate bound state.

In case of formation of a dimeric assembly, the amino acid residues 45 to 60 of both the chains come closer and interact strongly than other regions (Fig. 8C). Hence for proteinprotein dimer formation, the impact of this region is significant with high centrality value. In ligand unbound state, this region has diminished centrality value. For the oleate bound one, centrality value of the region suggests that this stretch is of importance but in lesser extent. It can be inferred that after binding of oleate those residues may have not so much contribution in the structural fluctuation to form the binding cavity.

To check if the binding induced dimer dissociation applies to other long chain fatty acids, we went on to computationally test our hypothesis with palmitate (another long chain fatty acid ligand for IFABP) (Fig. 7E). Our binding studies with palmitate reveal that palmitate binds to the same binding cleft as is the one for oleate. Centrality profile of palmitate bound IFABP reveals that residue 64 to 70 contributes maximally towards the intrinsic dynamics of the protein as is indicated by a high centrality value (Fig. 8D). Also some sporadic contributions were observed from the stretches formed of residues 35 to 40,46 to 51 along with the contribution from residue 100 to 110 (Fig. 8D). Centrality profile of palmitate bound IFABP clearly shows that residues significant for the formation of dimeric assembly contribute in greater extent. It suggests that ligand binding disrupts the propensity of IFABP towards the formation of higher order assembly.

\section{KARGER}


Sarkar-Banerjee et al.: Ameliorating Lipid Induced Cellular Toxicity by the Intestinal Fatty Acid Binding Protein

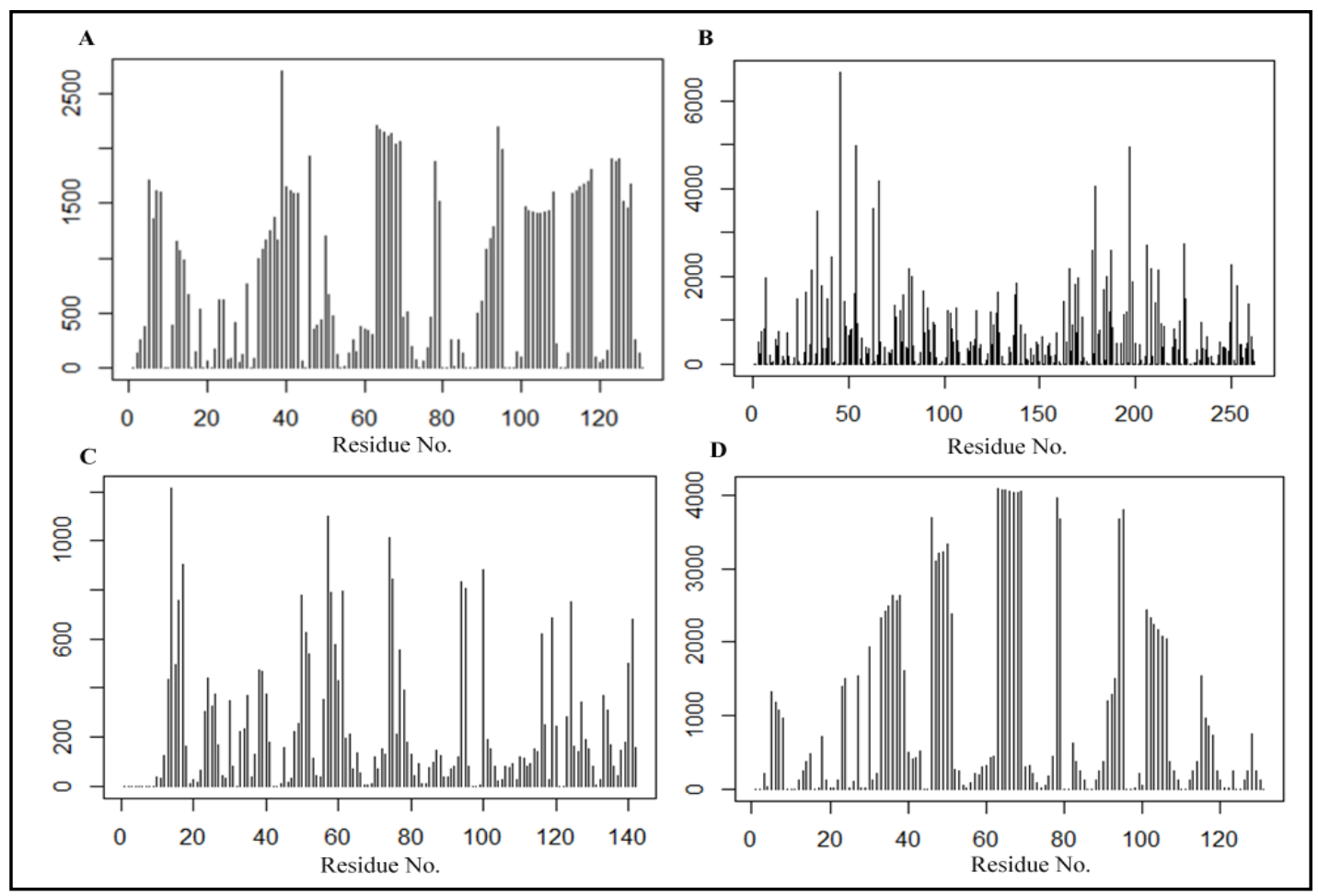

Fig. 8. Centrality profiles of (A) unbound IFABP, (B) the IFABP in its dimeric association, (C) oleate bound IFABP and (D) IFABP having palmitate as candidate ligand.

\section{Discussion}

FABPs are typically intracellular proteins known to bind their lipid ligands and help carry out various crucial functions [53-55] in cells making their ligands available for maintenance of cellular homeostasis. In the present study, we explored the functions of IFABP in regulating FA induced loss of mitochondrial dynamics and apoptosis. We chose mitochondria since this organelle is known for its role in FA oxidation and energy metabolism [56-59]. Mitochondria exist in healthy cells as a reticulate network with conserved membrane potential, which is crucial for efficient energy metabolism and dispersal of ATP throughout the cell [60]. The mitochondrial fusion-fission machinery maintains a dynamic balance of this tubular network, which is vital for energy dispersal and cellular homeostasis [60,61]. Mitochondrial membrane potential is compromised in cells undergoing stress and the reticulate networks are broken into smaller fragments, which also act as a signal for switching on the intrinsic / mitochondrial pathways of apoptosis. In our current study, we observed that ectopically expressed IFABP rescues mitochondria from the morphological impairments and prevents apoptosis induced by abundance of FA ligand oleate.

HeLa cells, which do not express IFABP, served as a heterologous platform for monitoring the dynamics of IFABP at single cell resolution. Not only that, adhered cells with their flatter surfaces make the FCS measurements much easier. Oleate was used at a dose $(0.5 \mathrm{mM})$ that induced stress response by switching on apoptotic pathways. With gradual increase in the oleate concentration from $0 \mathrm{mM}$ to $0.5 \mathrm{mM}$ through $0.3 \mathrm{mM}$, mitochondrial morphologies changed from long reticulate/tubular networks into fragmented, intermediate/punctate structures. Previously it was shown that high FA concentration causes intracellular stress with detrimental effects on downstream signaling cascades inducing oxidative stress, ER stress, etc [62].. Intracellular organelles like mitochondria were also affected, which in turn 
Sarkar-Banerjee et al.: Ameliorating Lipid Induced Cellular Toxicity by the Intestinal Fatty Acid Binding Protein

lead to decline in mitochondrial biogenesis, functions, etc $[25,28,63,64]$.. Our experimental results showed that the transition of tubular mitochondria to punctate fragments is concomitant with increased abundance of caspase 3 and apoptotic nuclear morphology.

We were curious to see if IFABP's interaction with its ligand could help rescue the FA burden in the cell. It was observed that with ectopic expression of IFABP, FA overload induced cell death decreased significantly marked with reduced apoptotic nuclear count. This observation suggested that IFABP had a protective function in cells under metabolic stress. Not only that, the mitochondrial morphology was also restored even in the presence of high FA concentrations. Hence our study showed that IFABP could rescue cells from FA burden-induced neglect.

In order to address the functional significance of IFABP, we chose a second cell-type in which the protein was expressed endogenously. We monitored the effect of $0.5 \mathrm{mM}$ FA dose in Caco-2 cells, and observed that apoptosis was induced with increased percentage of apoptotic nuclear count and expression of caspase 3 . The mitochondrial membrane potential was also compromised. Interestingly, the effect of FA induced metabolic stress was milder in Caco-2 cells than HeLa cells, both with respect to increased apoptotic nuclear count and the loss of mitochondrial membrane potential. One possible explanation can be that HeLa cells do not express IFABP, whereas the basal level expression of IFABP in wild type Caco-2 cells could help protect the cells by scavenging the excess FAs.

Further experiments were carried out to elucidate the role of IFABP by their ectopic expressions in Caco-2 cells. We observed that ectopically expressed IFABP provided significant protection against the increased FA dose, as revealed by conserved mitochondrial tubular structure after FA treatment. To investigate the importance of this protein in protecting mitochondrial dynamics under FA induced stress, IFABP was knocked down in Caco-2 cells. The mitochondrial morphology in the knockdown cells was significantly fragmented compared to the control cells indicating that the FA treated cells were no longer able to protect their mitochondrial morphology in the absence of IFABP. Not only that, these cells also undergone apoptosis.

Does this protein directly bind to its ligand while protecting the cells? We attempted to find a correlation between the function and structure of IFABP, thus addressing to the mechanism of its action. The question that followed was if IFABP's rescue-ability is correlated to its structure and its sub-cellular existence. Is this an intrinsic property of a carrier protein or there is more to its underlying structure for its behavior? To answer this, we monitored the localization of EGFP-tagged IFABP in the HeLa cells and measured the value of D (diffusion coefficient) using FCS. IFABP was earlier reported to exhibit diffused cytosolic localization [20]. In the present study, while the FA ligand was unavailable, IFABP was found to be soluble in the cytoplasm with persistent cluster formation within the cytosol and around the perinuclear region, a condition that was not observed in cells expressing the empty EGFP vector. As mentioned earlier, such perinuclear abundance of clusters could represent a reserve pool of the protein. The FAs and lipids form an integral part of the Golgi associated vesicle trafficking pathways and owing to the structural complexity of the Golgi apparatus and trans-Golgi network [65], the localization of proteins interacting with FAs and other lipids may appear condensed in the perinuclear compartment. Also, the pool of mitochondria is concentrated in the perinuclear compartment [66], thus explaining the relative abundance of IFABP in the perinuclear compartment. Our FCS measurements showed the presence of a lower $D$ value for these clusters along with $D^{\prime}$ s in the similar range as observed in the diffused cytoplasmic IFABPs. This heterogeneous localization of the protein can be explained by the structure of the protein itself. IFABP is a known $\beta$-sheet protein with a hydrophobic domain around the D-E turn [67]. Previously it was assumed that the short alpha helix present in the protein served as its ligand binding domain [68-70], but later it was found that in the intracellular environment, the helix-less IFABP (HL-IFABP) could also transfer its FA ligand [20]. It was also reported that the helix region helped the protein to transfer its ligand in the perinuclear region whereas the HL-IFABP was left diffused in the cytoplasm with its FA ligand [20]. Several in vitro works have established that the hydrophobic domain 
Fig. 9. Schematic overview of IFABP's role in modulating mitochondrial dynamics and protecting cells from apoptosis. In the absence of IFABP, abundant occurrence of fatty acid ligand (left side) causes loss of mitochondrial integrity, release of pro-apoptotic marker like caspase-3 in the cytosol and altered nuclear morphology, subsequently leading to apoptosis. The presence of IFABP (right side) lowers the potential risk of lipid toxicity and rescues cells from apoptosis and loss of mitochondrial integrity by binding to its fatty acid ligand, thereby protecting cells from lipid overload induced cellular stress.

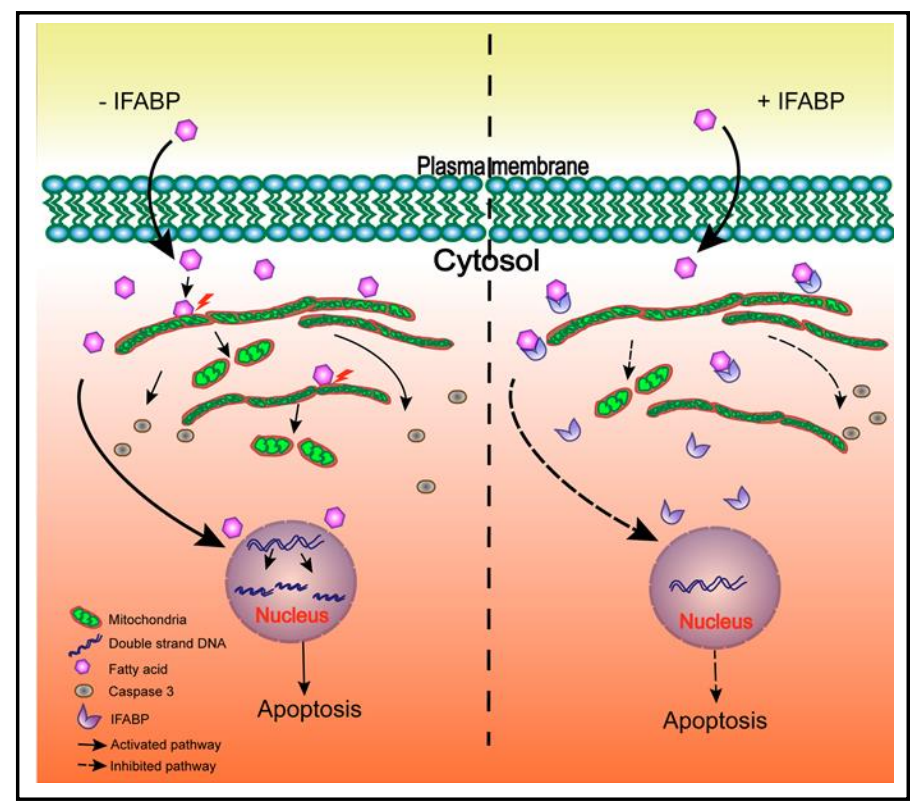

present in the protein helps it to fold and attain native structure properly [15, 71]. There are reports that suggest the roles of the hydrophobic patches of $\beta$-sheet proteins (66-69) [72-75] as also the alpha helices [76] to modulate the process of oligomerization. Hence, we hypothesized that during the lack of FA ligand in the cytosol, IFABP tends to form clusters by self-association (probably by forming non-covalent bonds between the hydrophobic patches of interacting proteins) and appear as bright dynamic species around the perinuclear region and within the cytosol. But with increasing availability of its ligand, the FAs would compete with the protein molecules and occupy the hydrophobic pockets out competing the proteins from self-association. This self-association $\mathrm{v} / \mathrm{s}$ oleate binding hypothesis was supported by the experimental data as there was no or considerably reduced clusters in the presence of FA (see Fig. 6D).

Some existing reports suggest that IFABP primarily localizes itself in regions around the vicinity of nucleus when the protein is not bound to ligand i.e. fatty acid [77]. This perinuclear localization along with some sporadic cytosolic clusters is found to get disrupted when fatty acid is available. The inherent tendency of IFABP to form perinuclear clusters can be explained in the light of some previous findings which gives an indication of a probable role of IFABP as indirect modulators of transcription factors which in turn demands the entry of IFABP inside cell nucleus [78]. There are reports suggesting that FABPs access the nucleus under certain conditions, and also target fatty acids (FA) to transcription factors, such as members of the peroxisome proliferator-activated receptor (PPAR) family [78]. Our in-cell spectroscopy which was done resorting to in-cell FCS showed an abundance of perinuclear clustering under conditions of oleate absence. As has been found with our computational studies, upon ligand binding the monomer-monomer interface gets destabilized owing to its closer proximity to the ligand binding cleft.

We further investigated the structural and ligand binding diversity using computational tools. To probe into the ligand induced IFABP cluster dissociation and the interplay of ligand binding sites and residues responsible for surface-surface interaction of bound IFABP monomers we resorted to an ensemble computational analysis. Our docking studies revealed that oleate can bind in multiple orientations and the site responsible for binding is at a close proximity of the monomer-monomer association span. Our protein-protein docking studies revealed that IFABP in its unbound state can indeed form higher order associations. The results are in compliance to the FCS finding. As revealed by our Betweenness Centrality plots, the residues majorly contributing to the internal dynamics of IFABP in monomeric state differs from those in the multimeric state. The alteration in the centrality profile in IFABP KARGER 
Sarkar-Banerjee et al.: Ameliorating Lipid Induced Cellular Toxicity by the Intestinal Fatty

Acid Binding Protein

upon higher order association reflects a re-orchestration of residue based contribution to the internal dynamics. The Centrality profile of IFABP in its ligand bound state was pretty disparate compared to that in ligand unbound state. This in turn provides a glimpse of residues chiefly contributing to the internal dynamics of IFABP upon oleate binding. Furthermore, our docking studies provide a plausible mechanistic insight into ligand binding suggesting that oleate bound conformational changes can trigger cluster dissociation owing to a relatively closer spatial proximity.

Our present study thus portrays two important aspects: First, IFABP's protective role against the FA overload-induced cellular stress. This protein not only has a protective function in the cells undergoing FA overload induced apoptotic cell death, but also has the potential to protect mitochondrial morphology under FA overload. Fig. 9 is the schematic representation of the functional importance of this protein in cellular environment. Second, the mechanism of IFABPs action has been addressed by its localization and dynamics in the cell. When there is a scarcity of the FA ligand in the cell, IFABPs form self-association contacts and appear as dynamics clusters in the cytoplasm and around the peri-nuclear regions. But with the availability of the ligand they undergo diffused cytoplasmic localization. FCS has been a very useful technique used here to measure the diffusion dynamics of the dual state of IFABP (both clusters and free cytoplasmic fractions). Together, our findings render IFABP to be a potential candidate for studying lipid induced mitochondrial dysfunction of enteric cells, which is relevant under fatal pathophysiological conditions.

Although the present study reveals a rescuing role of IFABP when the cells are under conditions of lipid stress, it is not explored if there can be other components of lipid metabolism which functions in synergy with IFABP and aids in the rescuing process. This study also could not address if the apoptotic stress is responsible for the mitochondrial degeneration or vice versa. However, our study clearly establishes that IFABP can help averting the possible toxic consequences of lipid stress by delaying the process of apoptotic death. Also future studies should address how the apoptotic regulation is getting re-orchestrated when IFABP is rescuing cells from apoptosis. As evidenced by our flow cytometry studies there were discernible shifts in the non-viable sub-population of cells when IFABP was expressed in cells under lipid stress in comparison to cells without transfected expression of IFABP. It would be worth exploring as to how the apoptotic cascade is reorienting itself during the lipid induced toxic phase and when IFABP is expressed.

\section{Conclusion}

Our present study thus portrays that IFABP has a protective function in the cells undergoing FA overload induced apoptotic cell death. Not only that, IFABP also has the potential to protect mitochondrial morphology under FA overload.

\section{Abbreviations}

FABP (Fatty acid binding protein); IFABP (Intestinal fatty acid binding protein); L-FABP (liver FABP); LCFA (long chain fatty acid); FBS (Fetal Bovine Serum); ROI (region of interest); ER (Endoplasmic Reticulum).

\section{Acknowledgements}

KC thanks the director, IICB for his support. SSB and TM thank their research fellowships from CSIR. SC thanks UGC for the senior research fellowship. DS thanks DST for the INSPIRE research fellowship. 


\section{Cellular Physiology Cell Physiol Biochem 2018;51:1658-1678 \begin{tabular}{ll|l} 
and Biochemistry & DOl: 10.1159/000495672 & $\begin{array}{l}\text { (c) } 2018 \text { The Author(s). Published by S. Karger AG, Basel } \\
\text { www.karger.com/cpb }\end{array}$ \\
\hline
\end{tabular}}

Sarkar-Banerjee et al.: Ameliorating Lipid Induced Cellular Toxicity by the Intestinal Fatty Acid Binding Protein

The present study has been funded by CSIR network project grant, UNSEEN and SERB funding (EMR/2016/000310).

KC planned the overall project outline. KC, SSB and SC designed the experiments. DS carried out the computational analysis. TM carried out the real time PCR and FACS analysis. The computational segment was designed by SC and DS.

\section{Disclosure Statement}

The authors declare that they have no conflicts of interest.

\section{References}

1 Montoudis A, Seidman E, Boudreau F, Beaulieu JF, Menard D, Elchebly M, Mailhot G, Sane AT, Lambert M, Delvin E, Levy E: Intestinal fatty acid binding protein regulates mitochondrion beta-oxidation and cholesterol uptake. J Lipid Res 2008;49:961-972.

-2 Falomir-Lockhart LJ, Laborde L, Kahn PC, Storch J, Corsico B: Protein-membrane interaction and fatty acid transfer from intestinal fatty acid-binding protein to membranes. Support for a multistep process. J Biol Chem 2006;281:13979-13989.

3 Storch J, Thumser AE: The fatty acid transport function of fatty acid-binding proteins. Biochim Biophys Acta 2000;1486:28-44.

4 Furuhashi M, Hotamisligil GS: Fatty acid-binding proteins: Role in metabolic diseases and potential as drug targets. Nat Rev Drug Discov 2008;7:489-503.

5 Hertzel AV, Bernlohr DA: Regulation of adipocyte gene expression by polyunsaturated fatty acids. Mol Cell Biochem 1998;188:33-39.

-6 Distel RJ, Robinson GS, Spiegelman BM: Fatty acid regulation of gene expression. Transcriptional and posttranscriptional mechanisms. J Biol Chem 1992;267:5937-5941.

-7 Furuhashi M, Ishimura S, Ota H, Miura T: Lipid chaperones and metabolic inflammation. Int J Inflam 2011;2011:642612.

-8 Sarkar S, Chattopadhyay K: Studies of early events of folding of a predominately $\beta$-sheet protein using fluorescence correlation spectroscopy and other biophysical methods. Biochemistry 2014;53:1393-1402.

-9 Sarkar-Banerjee S, Chowdhury S, Paul SS, Dutta D, Ghosh A, Chattopadhyay K: The non-native helical intermediate state may accumulate at low ph in the folding and aggregation landscape of the intestinal fatty acid binding protein. Biochemistry 2016;55:4457-4468.

10 Storch J, Corsico B: The emerging functions and mechanisms of mammalian fatty acid-binding proteins. Annu Rev Nutr 2008;28:73-95.

11 Agellon LB, Toth MJ, Thomson AB: Intracellular lipid binding proteins of the small intestine. Mol Cell Biochem 2002;239:79-82.

12 Olichon A, Baricault L, Gas N, Guillou E, Valette A, Belenguer P, Lenaers G: Loss of opa1 perturbates the mitochondrial inner membrane structure and integrity, leading to cytochrome c release and apoptosis. J Biol Chem 2003;278:7743-7746.

13 Weisiger RA: Mechanisms of intracellular fatty acid transport: Role of cytoplasmic-binding proteins. J Mol Neurosci 2007;33:42-44.

$>14$ Glatz JF, van Nieuwenhoven FA, Luiken JJ, Schaap FG, van der Vusse GJ: Role of membrane-associated and cytoplasmic fatty acid-binding proteins in cellular fatty acid metabolism. Prostaglandins Leukot Essent Fatty Acids 1997;57:373-378.

15 Kim K, Frieden C: Turn scanning by site-directed mutagenesis: Application to the protein folding problem using the intestinal fatty acid binding protein. Protein Sci 1998;7:1821-1828.

16 Chattopadhyay K, Saffarian S, Elson EL, Frieden C: Measurement of microsecond dynamic motion in the intestinal fatty acid binding protein by using fluorescence correlation spectroscopy. Proc Natl Acad Sci U S A 2002;99:14171-14176.

17 Kaikaus RM, Bass NM, Ockner RK: Functions of fatty acid binding proteins. Experientia 1990;46:617-630. 


\section{Cellular Physiology Cell Physiol Biochem 2018;51:1658-1678 \begin{tabular}{l|l|l|l|}
\hline DOI: 10.1159/000495672 2018 The Author(s). Published by S. Karger AG, Basel & and Biochemistry
\end{tabular} and Biochemistry}

Sarkar-Banerjee et al.: Ameliorating Lipid Induced Cellular Toxicity by the Intestinal Fatty Acid Binding Protein

18 Glatz JF, Borchers T, Spener F, van der Vusse GJ: Fatty acids in cell signalling: Modulation by lipid binding proteins. Prostaglandins Leukot Essent Fatty Acids 1995;52:121-127.

19 Glatz JF, van der Vusse GJ: Cellular fatty acid-binding proteins: Their function and physiological significance. Prog Lipid Res 1996;35:243-282.

-20 Karsenty J, Helal O, de la Porte PL, Beauclair-Deprez P, Martin-Elyazidi C, Planells R, Storch J, Gastaldi M: I-fabp expression alters the intracellular distribution of the bodipy c16 fatty acid analog. Mol Cell Biochem 2009;326:97-104.

21 Seifert EL, Fiehn O, Bezaire V, Bickel DR, Wohlgemuth G, Adams SH, Harper ME: Long-chain fatty acid combustion rate is associated with unique metabolite profiles in skeletal muscle mitochondria. PloS One 2010;5:e9834.

-22 Lieberthal W, Sheridan AM, Schwartz JH: Fatty acid-induced cytotoxicity: Differences in susceptibility between mdck cells and primary cultures of proximal tubular cells. J Lab Clin Med 1997;129:260-265.

-23 Rial E, Rodriguez-Sanchez L, Gallardo-Vara E, Zaragoza P, Moyano E, Gonzalez-Barroso MM: Lipotoxicity, fatty acid uncoupling and mitochondrial carrier function. Biochim Biophys Acta 2010;1797:800-806.

24 Boden G: Obesity and free fatty acids. Endocrinol Metab Clin North Am 2008;37:635-646, viii-ix.

25 Unger RH: Lipotoxic diseases. Annu Rev Med 2002;53:319-336.

26 Park KS, Wiederkehr A, Kirkpatrick C, Mattenberger Y, Martinou JC, Marchetti P, Demaurex N, Wollheim CB: Selective actions of mitochondrial fission/fusion genes on metabolism-secretion coupling in insulinreleasing cells. J Biol Chem 2008;283:33347-33356.

27 Benard G, Rossignol R: Ultrastructure of the mitochondrion and its bearing on function and bioenergetics. Antioxid Redox Signal 2008;10:1313-1342.

-28 Frezza C, Cipolat S, Martins de Brito O, Micaroni M, Beznoussenko GV, Rudka T, Bartoli D, Polishuck RS, Danial NN, De Strooper B, Scorrano L: Opa1 controls apoptotic cristae remodeling independently from mitochondrial fusion. Cell 2006;126:177-189.

29 Barsoum MJ, Yuan H, Gerencser AA, Liot G, Kushnareva Y, Graber S, Kovacs I, Lee WD, Waggoner J, Cui J, White AD, Bossy B, Martinou JC, Youle RJ, Lipton SA, Ellisman MH, Perkins GA, Bossy-Wetzel E: Nitric oxideinduced mitochondrial fission is regulated by dynamin-related gtpases in neurons. EMBO J 2006;25:39003911.

-30 Morel Y, Barouki R: Repression of gene expression by oxidative stress. Biochem J 1999;342 Pt 3:481-496.

-31 Susin SA, Zamzami N, Kroemer G: Mitochondria as regulators of apoptosis: Doubt no more. Biochim Biophys Acta 1998;1366:151-165.

-32 Green DR, Reed JC: Mitochondria and apoptosis. Science 1998;281:1309-1312.

-33 Zamzami N, Susin SA, Marchetti P, Hirsch T, Gomez-Monterrey I, Castedo M, Kroemer G: Mitochondrial control of nuclear apoptosis. J Exp Med 1996;183:1533-1544.

-34 Zamzami N, Marchetti P, Castedo M, Decaudin D, Macho A, Hirsch T, Susin SA, Petit PX, Mignotte B, Kroemer G: Sequential reduction of mitochondrial transmembrane potential and generation of reactive oxygen species in early programmed cell death. J Exp Med 1995;182:367-377.

-35 Sadqi M, Lapidus LJ, Munoz V: How fast is protein hydrophobic collapse? Proc Natl Acad Sci U S A 2003;100:12117-12122.

-36 Silow M, Tan YJ, Fersht AR, Oliveberg M: Formation of short-lived protein aggregates directly from the coil in two-state folding. Biochemistry 1999;38:13006-13012.

37 Kim PS, Baldwin RL: Intermediates in the folding reactions of small proteins. Annual review of biochemistry 1990;59:631-660.

-38 Banerjee P, Bandyopadhyay A: Cytosolic dynamics of annexin a6 trigger feedback regulation of hypertrophy via atrial natriuretic peptide in cardiomyocytes. J Biol Chem 2014;289:5371-5385.

-39 Dube N, Delvin E, Yotov W, Garofalo C, Bendayan M, Veerkamp JH, Levy E: Modulation of intestinal and liver fatty acid-binding proteins in caco-2 cells by lipids, hormones and cytokines. J Cell Biochem 2001;81:613620.

40 Banerjee P, Chander V, Bandyopadhyay A: Balancing functions of annexin a6 maintain equilibrium between hypertrophy and apoptosis in cardiomyocytes. Cell Death Dis 2015;6:e1873.

41 Huang CY, Chueh PJ, Tseng CT, Liu KY, Tsai HY, Kuo WW, Chou MY, Yang JJ: Zak re-programs atrial natriuretic factor expression and induces hypertrophic growth in h9c2 cardiomyoblast cells. Biochem Biophys Res Commun 2004;324:973-980. 


\section{Cellular Physiology Cell Physiol Biochem 2018;51:1658-1678 \begin{tabular}{l|l|l} 
and Biochemistry Published online: 30 November 2018 & $\begin{array}{l}\text { ○ } 2018 \text { The Author(s). Published by S. Karger AG, Basel } \\
\text { www.karger.com/cpb }\end{array}$ \\
\hline
\end{tabular}}

Sarkar-Banerjee et al.: Ameliorating Lipid Induced Cellular Toxicity by the Intestinal Fatty Acid Binding Protein

42 Bhattacharya D, Mazumder A, Miriam SA, Shivashankar GV: Egfp-tagged core and linker histones diffuse via distinct mechanisms within living cells. Biophys J 2006;91:2326-2336.

43 Mitra K, Lippincott-Schwartz J: Analysis of mitochondrial dynamics and functions using imaging approaches. Curr Protoc Cell Biol 2010;Chapter 4:1-21.

-44 Kim SA, Heinze KG, Schwille P: Fluorescence correlation spectroscopy in living cells. Nat Methods 2007;4:963-973.

-45 Wu J, Corbett AH, Berland KM: The intracellular mobility of nuclear import receptors and nls cargoes. Biophys J 2009;96:3840-3849.

-46 Comeau SR, Gatchell DW, Vajda S, Camacho CJ: Cluspro: A fully automated algorithm for protein-protein docking. Nucleic Acids Res 2004;32:W96-W99.

47 Zimmerman AW, van Moerkerk HT, Veerkamp JH: Ligand specificity and conformational stability of human fatty acid-binding proteins. Int J Biochem Cell Biol 2001;33:865-876.

$\checkmark 48$ Wiesner S, Kurian E, Prendergast FG, Halle B: Water molecules in the binding cavity of intestinal fatty acid binding protein: Dynamic characterization by water17o and $2 \mathrm{~h}$ magnetic relaxation dispersion 1. J Mol Biol 1999;286:233-246.

49 Gao AW, Canto C, Houtkooper RH: Mitochondrial response to nutrient availability and its role in metabolic disease. EMBO Mol Med 2014;6:580-589.

50 Banks DS, Fradin C: Anomalous diffusion of proteins due to molecular crowding. Biophys J 2005;89:29602971.

51 Saha B, Chowdhury S, Sanyal D, Chattopadhyay K, Suresh Kumar G: Comparative study of toluidine blue o and methylene blue binding to lysozyme and their inhibitory effects on protein aggregation. ACS Omega 2018;3:2588-2601.

52 Kim K, Frieden C: Turn scanning by site-directed mutagenesis: Application to the protein folding problem using the intestinal fatty acid binding protein. Protein Sci 1998;7:1821-1828.

53 Darimont C, Gradoux N, Persohn E, Cumin F, De Pover A: Effects of intestinal fatty acid-binding protein overexpression on fatty acid metabolism in caco-2 cells. J Lipid Res 2000;41:84-92.

54 Tan NS, Shaw NS, Vinckenbosch N, Liu P, Yasmin R, Desvergne B, Wahli W, Noy N: Selective cooperation between fatty acid binding proteins and peroxisome proliferator-activated receptors in regulating transcription. Mol Cell Biol 2002;22:5114-5127.

55 Wiederkehr A, Wollheim CB: Linking fatty acid stress to beta-cell mitochondrial dynamics. Diabetes 2009;58:2185-2186.

56 Tyni T, Paetau A, Strauss AW, Middleton B, Kivela T: Mitochondrial fatty acid beta-oxidation in the human eye and brain: Implications for the retinopathy of long-chain 3-hydroxyacyl-coa dehydrogenase deficiency. Pediatr Res 2004;56:744-750.

57 Fillmore N, Mori J, Lopaschuk GD: Mitochondrial fatty acid oxidation alterations in heart failure, ischaemic heart disease and diabetic cardiomyopathy. Br J Pharmacol 2014;171:2080-2090.

-58 Chung S, Dzeja PP, Faustino RS, Perez-Terzic C, Behfar A, Terzic A: Mitochondrial oxidative metabolism is required for the cardiac differentiation of stem cells. Nat Clin Pract Cardiovasc Med 2007;4:S60-67.

-59 Benani A, Troy S, Carmona MC, Fioramonti X, Lorsignol A, Leloup C, Casteilla L, Penicaud L: Role for mitochondrial reactive oxygen species in brain lipid sensing: Redox regulation of food intake. Diabetes 2007;56:152-160.

-60 Benard G, Bellance N, James D, Parrone P, Fernandez H, Letellier T, Rossignol R: Mitochondrial bioenergetics and structural network organization. J Cell Sci 2007;120:838-848.

-61 Heath-Engel HM, Shore GC: Mitochondrial membrane dynamics, cristae remodelling and apoptosis. Biochim Biophys Acta 2006;1763:549-560.

62 Borradaile NM, Buhman KK, Listenberger LL, Magee CJ, Morimoto ET, Ory DS, Schaffer JE: A critical role for eukaryotic elongation factor 1a-1 in lipotoxic cell death. Mol Biol Cell 2006;17:770-778.

63 Unger RH, Orci L: Lipoapoptosis: Its mechanism and its diseases. Biochim Biophys Acta 2002;1585:202212.

64 Bernardi P, Penzo D, Wojtczak L: Mitochondrial energy dissipation by fatty acids. Mechanisms and implications for cell death. Vitam Horm 2002;65:97-126.

65 Tan X, Banerjee P, Guo H-F, Ireland S, Pankova D, Ahn Y-h, Nikolaidis IM, Liu X, Zhao Y, Xue Y: Epithelialto-mesenchymal transition drives a pro-metastatic golgi compaction process through scaffolding protein paqr11. J Clin Invest 2017;127:117-131. 


\section{Cellular Physiology and Biochemistry}

Cell Physiol Biochem 2018;51:1658-1678

\begin{tabular}{l|c|c|c|}
\hline DOI: 10.1159/000495672 & (C) 2018 The Author(s). Published by S. Karger AG, Basel
\end{tabular}

ished online: 30 November 2018 www.karger.com/cpb

Sarkar-Banerjee et al:: Ameliorating Lipid Induced Cellular Toxicity by the Intestinal Fatty

Acid Binding Protein

66 Banerjee P, Chander V, Bandyopadhyay A: Balancing functions of annexin a6 maintain equilibrium between hypertrophy and apoptosis in cardiomyocytes. Cell Death Dis 2015;6:e1873.

67 Chattopadhyay K, Zhong S, Yeh SR, Rousseau DL, Frieden C: The intestinal fatty acid binding protein: The role of turns in fast and slow folding processes. Biochemistry 2002;41:4040-4047.

68 Corsico B, Cistola DP, Frieden C, Storch J: The helical domain of intestinal fatty acid binding protein is critical for collisional transfer of fatty acids to phospholipid membranes. Proc Natl Acad Sci U S A 1998;95:12174-12178.

69 Corsico B, Liou HL, Storch J: The alpha-helical domain of liver fatty acid binding protein is responsible for the diffusion-mediated transfer of fatty acids to phospholipid membranes. Biochemistry 2004;43:36003607.

70 Corsico B, Franchini GR, Hsu KT, Storch J: Fatty acid transfer from intestinal fatty acid binding protein to membranes: Electrostatic and hydrophobic interactions. J Lipid Res 2005;46:1765-1772.

71 Yeh SR, Ropson IJ, Rousseau DL: Hierarchical folding of intestinal fatty acid binding protein. Biochemistry 2001;40:4205-4210.

72 Viet MH, Ngo ST, Lam NS, Li MS: Inhibition of aggregation of amyloid peptides by beta-sheet breaker peptides and their binding affinity. J Phys Chem B 2011;115:7433-7446.

73 Cheon M, Chang I, Mohanty S, Luheshi LM, Dobson CM, Vendruscolo M, Favrin G: Structural reorganisation and potential toxicity of oligomeric species formed during the assembly of amyloid fibrils. PLoS Comput Biol 2007;3:1727-1738.

74 Favrin G, Irback A, Mohanty S: Oligomerization of amyloid abeta16-22 peptides using hydrogen bonds and hydrophobicity forces. Biophys J 2004;87:3657-3664.

75 Lu Y, Derreumaux P, Guo Z, Mousseau N, Wei G: Thermodynamics and dynamics of amyloid peptide oligomerization are sequence dependent. Proteins 2009;75:954-963.

76 Sarkar-Banerjee S, Sayyed-Ahmad A, Prakash P, Cho K-J, Waxham MN, Hancock JF, Gorfe AA: Spatiotemporal analysis of k-ras plasma membrane interactions reveals multiple high order homo-oligomeric complexes. J Am Chem Soc 2017;139:13466-13475.

77 Karsenty J, Helal O, de la Porte PL, Beauclair-Deprez P, Martin-Elyazidi C, Planells R, Storch J, Gastaldi M: I-fabp expression alters the intracellular distribution of the bodipy c16 fatty acid analog. Mol Cell Biochem 2009;326:97-104.

78 Storch J, McDermott L: Structural and functional analysis of fatty acid-binding proteins. J Lipid Res 2009;50:S126-S131. 